Article

\title{
An Electronic Tongue Designed to Detect Ammonium Nitrate in Aqueous Solutions
}

\author{
Inmaculada Campos ${ }^{1,2}$, Lluis Pascual ${ }^{1,3}$, Juan Soto ${ }^{1,3}$, Luis Gil-Sánchez ${ }^{1,4}$ and \\ Ramón Martínez-Máñez ${ }^{1,2,3, *}$
}

1 Centro de Reconocimiento Molecular y Desarrollo Tecnológico (IDM), Unidad Mixta Universidad Politécnica de Valencia-Universidad de Valencia de Valéncia, Camino de Vera s/n, E-46022 Valencia, Spain; E-Mails: incasan2@upvnet.upv.es (I.C); llpasvi@upvnet.upv.es (L.P.); jsotoca@upv.es (J.S.); lgil@eln.upv.es (L.G.-S.)

2 CIBER de Bioingeniería, Biomateriales y Nano medicina (CIBER-BBN), Bellaterra, E-08193 Barcelona, Spain

3 Departamento de Química. Universidad Politécnica de Valencia. Camino de Vera s/n., E-46022 Valencia, Spain

4 Departamento de Ingeniería Electrónica. Universidad Politécnica de Valencia, Camino de Vera, s/n. E-46022 Valencia, Spain

* Author to whom correspondence should be addressed; E-Mail: rmaez@qim.upv.es; Tel.: +34-963-877-343; Fax: +34-963-879-349.

Received: 20 August 2013; in revised form: 2 October 2013 / Accepted: 15 October 2013 / Published: 18 October 2013

\begin{abstract}
An electronic tongue has been developed to monitor the presence of ammonium nitrate in water. It is based on pulse voltammetry and consists of an array of eight working electrodes ( $\mathrm{Au}$; Pt; Rh; Ir; Cu; Co; Ag and Ni) encapsulated in a stainless steel cylinder. In a first step the electrochemical response of the different electrodes was studied in the presence of ammonium nitrate in water in order to further design the wave form used in the voltammetric tongue. The response of the electronic tongue was then tested in the presence of a set of 15 common inorganic salts; i.e.; $\mathrm{NH}_{4} \mathrm{NO}_{3} ; \mathrm{MgSO}_{4} ; \mathrm{NH}_{4} \mathrm{Cl} ; \mathrm{NaCl} ; \mathrm{Na}_{2} \mathrm{CO}_{3}$; $\left(\mathrm{NH}_{4}\right)_{2} \mathrm{SO}_{4} ; \mathrm{MgCl}_{2} ; \mathrm{Na}_{3} \mathrm{PO}_{4} ; \mathrm{K}_{2} \mathrm{SO}_{4} ; \mathrm{K}_{2} \mathrm{CO}_{3} ; \mathrm{CaCl}_{2} ; \mathrm{NaH}_{2} \mathrm{PO}_{4} ; \mathrm{KCl} ; \mathrm{NaNO}_{3} ; \mathrm{K}_{2} \mathrm{HPO}_{4}$. A PCA plot showed a fairly good discrimination between ammonium nitrate and the remaining salts studied. In addition Fuzzy Art map analyses determined that the best classification was obtained using the Pt; $\mathrm{Co}$; $\mathrm{Cu}$ and $\mathrm{Ni}$ electrodes. Moreover; PLS regression allowed the creation of a model to correlate the voltammetric response of the
\end{abstract}


electrodes with concentrations of ammonium nitrate in the presence of potential interferents such as ammonium chloride and sodium nitrate.

Keywords: ammonium nitrate; electronic tongue; PCA; fuzzy ARTMAP; PLS

\section{Introduction}

Ammonium nitrate $\left(\mathrm{NH}_{4} \mathrm{NO}_{3}\right)$ is generally found in the form of odourless, transparent, hygroscopic deliquescent crystals or white granules. $\mathrm{NH}_{4} \mathrm{NO}_{3}$ is the cheapest source of oxygen available in a condensed form for commercial explosives. The original experiments with $\mathrm{NH}_{4} \mathrm{NO}_{3}$, as a component of explosive mixtures began in the second half of the nineteenth century. Grindel and Robin were the first to use $\mathrm{NH}_{4} \mathrm{NO}_{3}$ in explosive formulations as a replacement of potassium nitrate in black powder [1] and in 1867, the Sweedish chemists Ohlosson and Norrbin patented an explosive called Ammoniakus [2]. The explosive properties of $\mathrm{NH}_{4} \mathrm{NO}_{3}$, such as sensitivity to detonation, impact and heat, rate of detonation, etc. were reported first in the beginning of the last century. $\mathrm{NH}_{4} \mathrm{NO}_{3}$ is usually used by itself, in conjunction with fuels or in mixtures with solid fuels and sensitizers such as nitroglycerine and TNT [3]. The use of $\mathrm{NH}_{4} \mathrm{NO}_{3}$ with fuel oil provides a very widely used explosive usually called ANFO. Aluminum is also sometimes added to increase the sensitiveness of the explosive mixture. Though the idea of using $\mathrm{NH}_{4} \mathrm{NO}_{3}$ with a fuel as a commercial explosive formulation was proposed as early as 1867 (vide ante), ANFO explosives were only finally developed in 1955. They can be made on-site in a mobile unit and are inexpensive and safe to handle. However, they have low strength and detonation velocity and cannot be used in the presence of water [4,5]. The detonation velocity was improved by the creation of water-based explosives. These explosives were developed by mixing $\mathrm{NH}_{4} \mathrm{NO}_{3}$ solutions with oils in different compositions. The micro-droplets of the emulsion explosive offer the advantage of intimate contact between fuel and oxidizer and outperform conventional water based slurries. In fact, ANFO and water-based commercial explosives have largely displaced the nitroglycerine-based dynamites, thanks to their low cost, safety, versatile performance and application.

Identification and quantification of explosives has constituted an emerging and important topic of interest due to their relevant role in security threat. Moreover, it has been widely discussed that the detection of explosive compounds is a highly significant task in forensics and antiterrorist activities. As the danger of terrorism is increasing, the demand for reliable and rapid methods for screening luggage or to analyze suspect samples is also growing up. Apart of the classical procedures for the individual detection of nitrate and ammonium, several methods have been reported in the literature for the simultaneous speciation of $\mathrm{NO}_{3}{ }^{-}$and $\mathrm{NH}_{4}{ }^{+}$, among them, perhaps the most common in the use of ion chromatography [6]. In general ion chromatography method offers good reproducibility, high sensitivity and selectivity $[7,8]$. Nevertheless, for the determination of these inorganic nitrogen species two separate sets must be applied: one with an anion-exchange column for the determination of $\mathrm{NO}_{3}{ }^{-}$ and another with a cation-exchange column for the determination of $\mathrm{NH}_{4}{ }^{+}$. Hence, the simultaneous determination of nitrogen species requires a sophisticated assembly. Moreover these methods use reagents and expensive columns that must be periodically cleaned and calibrated as their performances 
change with time. These technical requirements unfortunately did not permit a routine and in situ or at site use of these procedures [9-11].

Electronic tongues (ETs) are multisensory systems, which consist of a number of low-selectivity sensors and use advanced mathematical procedures for signal processing based on Pattern Recognition and Multivariate data analysis. These electronic devices are inspired by the human taste system and as in nature ET, are constituted of a limited number of receptors that can respond to several stimuli of different nature. The first voltammetric electronic tongue was proposed by Winquist and used metallic electrodes to detect different samples of several juices, milk and phosphate buffer [12].

Following these concepts and taking into account our interest in the design of sensing systems and probes for the detection of explosives [13-15] and our experience in the design of electronic tongue devices for several applications [16-18], we report herein the use of an electronic tongue for the discrimination of $\mathrm{NH}_{4} \mathrm{NO}_{3}$ versus other common salts in an aqueous environment. The aim of this work is develop a rapid, simple and low-cost method for the detection of levels of ammonium nitrate in water samples using voltammetry as analytical tool. The electronic tongue is based in voltammetry and uses a set of simple metallic electrodes ( $\mathrm{Au}, \mathrm{Pt}, \mathrm{Rh}, \mathrm{Ir}, \mathrm{Cu}, \mathrm{Co}, \mathrm{Ag}$ and Ni). Multivariate analysis including Cross validation, Principal Components Analysis and Partial Least Square (PLS) techniques have also been applied in this study.

\section{Experimental Section}

\subsection{Sample Preparation}

Discrimination studies were carried out using 15 inorganic salts, i.e., $\mathrm{NH}_{4} \mathrm{NO}_{3}, \mathrm{MgSO}_{4}, \mathrm{NH}_{4} \mathrm{Cl}$, $\mathrm{NaCl}, \mathrm{Na}_{2} \mathrm{CO}_{3},\left(\mathrm{NH}_{4}\right)_{2} \mathrm{SO}_{4}, \mathrm{MgCl}_{2}, \mathrm{Na}_{3} \mathrm{PO}_{4}, \mathrm{~K}_{2} \mathrm{SO}_{4}, \mathrm{~K}_{2} \mathrm{CO}_{3}, \mathrm{CaCl}_{2}, \mathrm{NaH}_{2} \mathrm{PO}_{4}, \mathrm{KCl}, \mathrm{NaNO}_{3}, \mathrm{~K}_{2} \mathrm{HPO}_{4}$ (with purity of $99.9 \%$ from Sigma-Aldrich, Madrid, Spain). All these samples were prepared at a concentration of $10^{-2} \mathrm{~mol} \cdot \mathrm{L}^{-1}$ in water. The samples were measured in quintuplicate.

Moreover quantification studies were carried out via a factorial experimental design approach which was applied to create a system of three compounds/three levels. By using the experimental design (MODDE 8.0, Umetrics, Umeå, Sweden) the number of samples was generated. This design takes into account the possible interactions between the analytes and provides the minimum number of solutions which represent the system and determine the concentration of each compound in each sample. The final set included 20 samples prepared by addition of three selected compounds $\left(\mathrm{NH}_{4} \mathrm{NO}_{3}\right.$, $\mathrm{NaCl}$ and $\left.\mathrm{NH}_{4} \mathrm{Cl}\right)$ into phosphate buffer $\left(\mathrm{Na}_{2} \mathrm{HPO}_{4}, 10^{-2} \mathrm{~mol} \cdot \mathrm{L}^{-1}\right.$ at $\left.\mathrm{pH} 7\right)$. The Table 1 displays the concentration levels of the samples which were: blank, low $\left(1 \times 10^{-3} \mathrm{~mol} \cdot \mathrm{L}^{-1}\right)$, medium $\left(5 \times 10^{-3} \mathrm{~mol} \cdot \mathrm{L}^{-1}\right)$ and high $\left(1 \times 10^{-2} \mathrm{~mol} \cdot \mathrm{L}^{-1}\right)$. All samples were measured once and in random order to minimize possible error due to memory of the electrodes. 
Table 1. Concentrations of samples prepared by addition of three selected compounds $\left(\mathrm{NH}_{4} \mathrm{NO}_{3}, \mathrm{NaCl}\right.$ and $\mathrm{NH}_{4} \mathrm{Cl}$ ) into water (phosphate buffer $10^{-2} \mathrm{~mol} \cdot \mathrm{L}^{-1}, \mathrm{pH}$ ).

\begin{tabular}{cccc}
\hline Sample & $\begin{array}{c}\mathbf{N H}_{\mathbf{4}} \mathbf{N O}_{\mathbf{3}} \\
\left(\mathbf{m o l} \cdot \mathbf{L}^{-\mathbf{1}}\right) \mathbf{\mathbf { 1 0 } ^ { - 3 }}\end{array}$ & $\begin{array}{c}\mathbf{N a C l} \\
\left(\mathbf{m o l} \cdot \mathbf{L}^{-\mathbf{1}}\right) \times \mathbf{1 \mathbf { 1 } ^ { - 3 }}\end{array}$ & $\begin{array}{c}\mathbf{N H}_{\mathbf{4}} \mathbf{C l} \\
\left(\mathbf{m o l} \cdot \mathbf{L}^{-\mathbf{1}}\right) \times \mathbf{\mathbf { 1 0 } ^ { - 3 }}\end{array}$ \\
\hline 1 & 10 & 10 & 1 \\
2 & 1 & 10 & 10 \\
3 & 5 & 5 & 5 \\
4 & 10 & 1 & 5 \\
5 & 1 & 10 & 1 \\
6 & 10 & 5 & 10 \\
7 & 10 & 10 & 10 \\
8 & 10 & 10 & 10 \\
9 & 10 & 10 & 10 \\
10 & 1 & 1 & 1 \\
11 & 1 & 1 & 10 \\
12 & 10 & 1 & 10 \\
13 & 10 & 10 & 10 \\
14 & 1 & 1 & 5 \\
15 & 5 & 1 & 10 \\
16 & 5 & 1 & 1 \\
17 & 10 & 1 & 1 \\
18 & 10 & 1 & 10 \\
19 & 0 & 0 & 0 \\
20 & 0 & 0 & 0 \\
\hline
\end{tabular}

\subsection{Electronic Tongue Based on Pulse Voltammetry}

The electronic tongue device used in this work consists of eight working electrodes array (Au, Pt, $\mathrm{Rh}, \mathrm{Ir}, \mathrm{Cu}, \mathrm{Co}, \mathrm{Ag}$ and $\mathrm{Ni}$ with purity of $99.9 \%$ and $1 \mathrm{~mm}$ diameter from Sigma-Aldrich) housed inside a stainless steel cylinder used at the same time as both the body of the electronic tongue system and as counter-electrode (See Figure 1). The electronic tongue was inspired in a similar design reported by Winquist et al. [12]. Noble electrodes (i.e., Au, Pt Rh and Ir) are selected due to their capability to adsorb different chemical species on their surface. Moreover non-noble electrodes $(\mathrm{Cu}$, $\mathrm{Co}$, Ag and $\mathrm{Ni}$ ) were also used due to the potential occurrence of chemical reactions between species in the solution and the oxidised metal. In addition a Saturated Calomel Electrode (SCE) was used as reference electrode.

The generation of pulses and recording of current data were performed in a potentiostat-galvanostat Autolab (Eco Chemie, Utrecht, The Netherlands), controlled with the General Purpose Electrochemical System software (GPES Version 4.9). The measuring procedure was carried out by applying 10 pulses of fixed potential to the electrodes (range of pulses from -0.5 to $+0.4 \mathrm{~V}$ relative to the SCE electrode, with duration of $50 \mathrm{~ms}$ ). A total of 4800 currents ( 60 points for pulse $\times 10$ pulses $\times 8$ electrodes) were recorded for each sample. The dimensions of the data sets were $40 \times 4,800$ and $20 \times 4,800$ for discriminant and quantification studies, respectively. Whereas the dimensions of the final data set (including only the four electrodes which provides better results) were $40 \times 2,400$ and $20 \times 2,400$, respectively. 
Figure 1. The electronic tongue formed by non-noble electrodes.

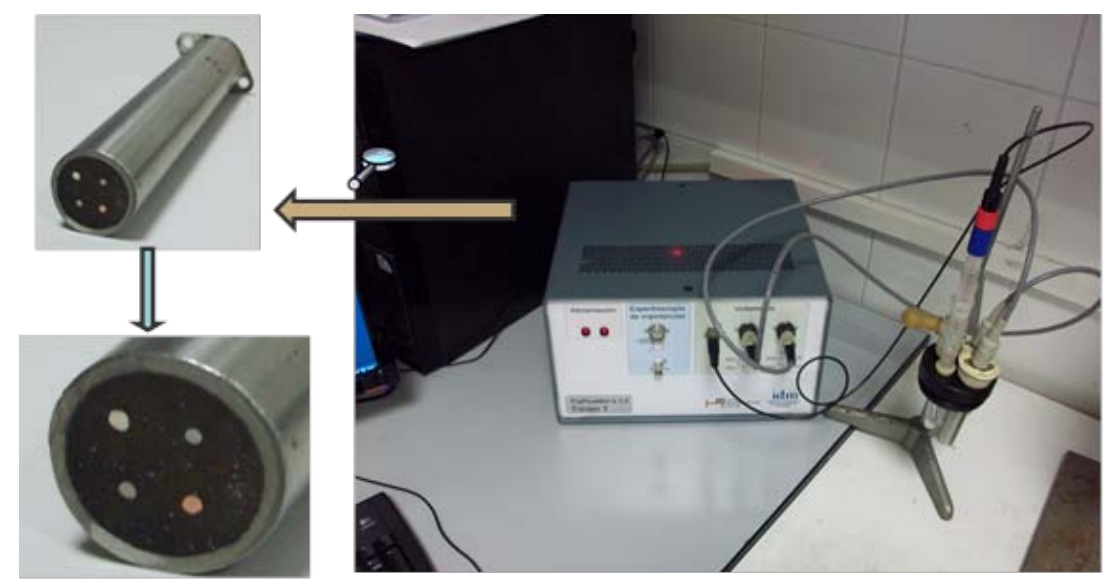

Before use, the electrode surface was prepared by mechanical polishing with an emery paper, and rinsed with distilled water. Then it was polished on a felt pad with $0.05 \mu \mathrm{m}$ alumina polish from BASi (West Lafayette, IN, USA), washed with distilled water and polished again on a nylon pad with 15, 3 and $1 \mu \mathrm{m}$ diamond polishes, to produce a smooth, mirror-like electrode surface. Later in the development of series of measurements, only a simple diamond polishing was made.

\subsection{Cyclic Voltammetry Studies}

The electrochemical characterization of $\mathrm{NH}_{4} \mathrm{NO}_{3}$ solutions were performed using an Autolab PGSTAT100 instrument (Eco Chemie, Utrecht, The Netherlands). The electrochemical characterization was carried out using aqueous solution $0.01 \mathrm{~mol} \cdot \mathrm{L}^{-1}$ of ammonium nitrate at $\mathrm{pH} 7$ buffered with phosphate at a concentration of $0.01 \mathrm{~mol} \cdot \mathrm{L}^{-1}$. All measurements were performed at room temperature $\left(20 \pm 2{ }^{\circ} \mathrm{C}\right.$ ). The electrochemical experiments were carried out using the electronic tongue (containing a set of electrodes housed into a homemade stainless steel cylinder). A SCE was used as reference electrode. The cyclic voltammetry experiments were carried out at a scan rate of $100 \mathrm{mV} \cdot \mathrm{s}^{-1}$.

\subsection{Data Management}

Multivariate data analysis (MVDA) was used to treat the raw data obtained from the instruments. Principal component analysis (PCA) is an example of such an MVDA which explains the variance in the experimental data [19]. The PCA produces a score plot that is visualizing differences between the observations or experiments. This can be used for classifications or groupings of the observations. The first principal component (PC1) is the dimension along which the observations are maximally separated, or spread out. The second principal component (PC2) is the linear combination with maximal variance in a direction orthogonal to the first principal component, and so on [20].

For the instrumental data, the used data matrix was consisted of the number of experiments as number of objects, and the obtained current responses as variables [21]. Data were standardized since standardization gives all the variables the same variance and all the variables have the same influence of the estimation of the components.

A widely used method for the classification of different samples is artificial neural networks. This kind of networks is formed by mathematical algorithms which coefficients relate the values of multiple 
inputs with different output categories. To work with neural networks a training stage is required which sets the value of these coefficients, and a subsequent validation step which shows the network response to new data.

There are different types of networks, such as Fuzzy-Artmap type. This type of network is based on the so-called adaptive resonance theory (ART) [22], which develops models capable of rapid stable learning of recognition categories in response to arbitrary sequences of input patterns. The Fuzzy Artmap combines two ART units into a supervised learning structure where the first unit takes the input data and the second unit takes the correct output data [23] and it has demonstrated to show a good behaviour with low computational cost for a small number of data and groups of varying size [24].

To analyze the power of classification of the neural network applied to the data measured 'leave-one-out' cross-validation technique was applied. This cross-validation method extracts one data vector and the training of the network is done with the remaining data, in our case data are 74 measurements. The validation of the network is done with the extracted data. The validation is to determine if the network classifies correctly the extracted data. This process is repeated by using all the data, in our case 75 times. The discrimination capacity of the network is determined by the percentage of accurate classifications of data.

For quantitative analysis studies PLS techniques were applied. The main objective of PLS regression is to predict $\mathrm{Y}$ from $\mathrm{X}$, by simultaneous decomposition of those matrixes or vectors in a group of components (latent variables) which explain as much as possible the covariance of $\mathrm{X}$ and $\mathrm{Y}$ [25]. Prediction models are created by using the calibration set (standards) and the collected data. Prior to build the model, "leave-one-out" cross validation technique was used to evaluate the adequacy of the experimental data, and to select the quantity of latent variable, indicating that 7 latent variables explain the $89 \%$ of the accumulated variance. All statistical analysis was performed with the software Solo (version 6.5, Eigenvector Research, Inc., Wenatchee, WA, USA).

\section{Results and Discussion}

\subsection{Voltammetric Studies}

In order to explore more in detail the response of the metallic electrodes in the presence of $\mathrm{NH}_{4} \mathrm{NO}_{3}$, the electrochemical behaviour of this salt was studied in water by cyclic voltammetry $\left(10^{-2} \mathrm{~mol} \cdot \mathrm{L}^{-1}\right.$ phosphate buffer at $\mathrm{pH}$ 7) using $\mathrm{Au}, \mathrm{Pt}, \mathrm{Rh}, \mathrm{Ir}, \mathrm{Cu}, \mathrm{Co}, \mathrm{Ag}$ and $\mathrm{Ni}$ as working electrodes. As it is well-known, the voltammetric response of a certain compound depends on the intrinsic chemical nature of the both the electrode and the electrochemical characteristics of the redox-active species. The electronic tongue device relies in the concept that subtle differences between relatively similar compounds might be reflected in the specific differential voltammetric response of the electrode ensemble.

In the cyclic voltammetry studies, ammonium nitrate displayed an oxidation peak at $250 \mathrm{mV}$ and a reduction process at $-160 \mathrm{mV}$ vs. SCE using Ag as electrode. This behaviour was clearly different to that found when $\mathrm{Cu}$ was used. In the latter case a reduction peak at $-450 \mathrm{mV}$ vs. SCE was found together with an increase in the corrosion of the copper electrode (see Figure 2). When a Co electrode 
was used, the presence of ammonium nitrate also caused an increment in the corrosion of the metal which started at $-200 \mathrm{mV}$ but in this case no reduction peaks were found. For platinum as electrode two small redox peaks were found at -250 and $-500 \mathrm{mV}$. Finally, when nickel electrode is used as working electrode, the ammonium nitrate does not show the presence of redox peaks and only changes in the ohmic current was observed. Voltammetry studies on $\mathrm{NH}_{4} \mathrm{NO}_{3}$ with other electrodes tested (not shown) displayed minor changes in the ohmic current. Nevertheless it has to be taken into account that in recent studies it has been pointed out that the lack of clear redox processes does not hamper the use of voltammetric electronic tongues bearing in mind that changes induced by chemical species, in the currents from the reduction or oxidation of water, in the equilibrium potential of the electrodes or the presence of non-Faradic effects due to chemical adsorption on the electrode, might also be used for multivariate data analysis and chemical discrimination [15]. The performed electrochemical studies suggested that the use of these metals, in an electronic tongue format, may be suitable to detect ammonium nitrate in solution and to discriminate its presence from the existence of other salts.

Figure 2. Cyclic voltammograms of the solvent ( $\mathrm{pH} 7$ buffered with $0.01 \mathrm{~mol} \cdot \mathrm{L}^{-1}$ phosphate buffer (solid line) and of $0.001 \mathrm{~mol} \cdot \mathrm{L}^{-1} \mathrm{NH}_{4} \mathrm{NO}_{3}$ solutions (dashed line) measured at $100 \mathrm{mV} \cdot \mathrm{s}^{-1}$ using silver (a), copper (b), platinum (c), cobalt (d) and nickel (e).
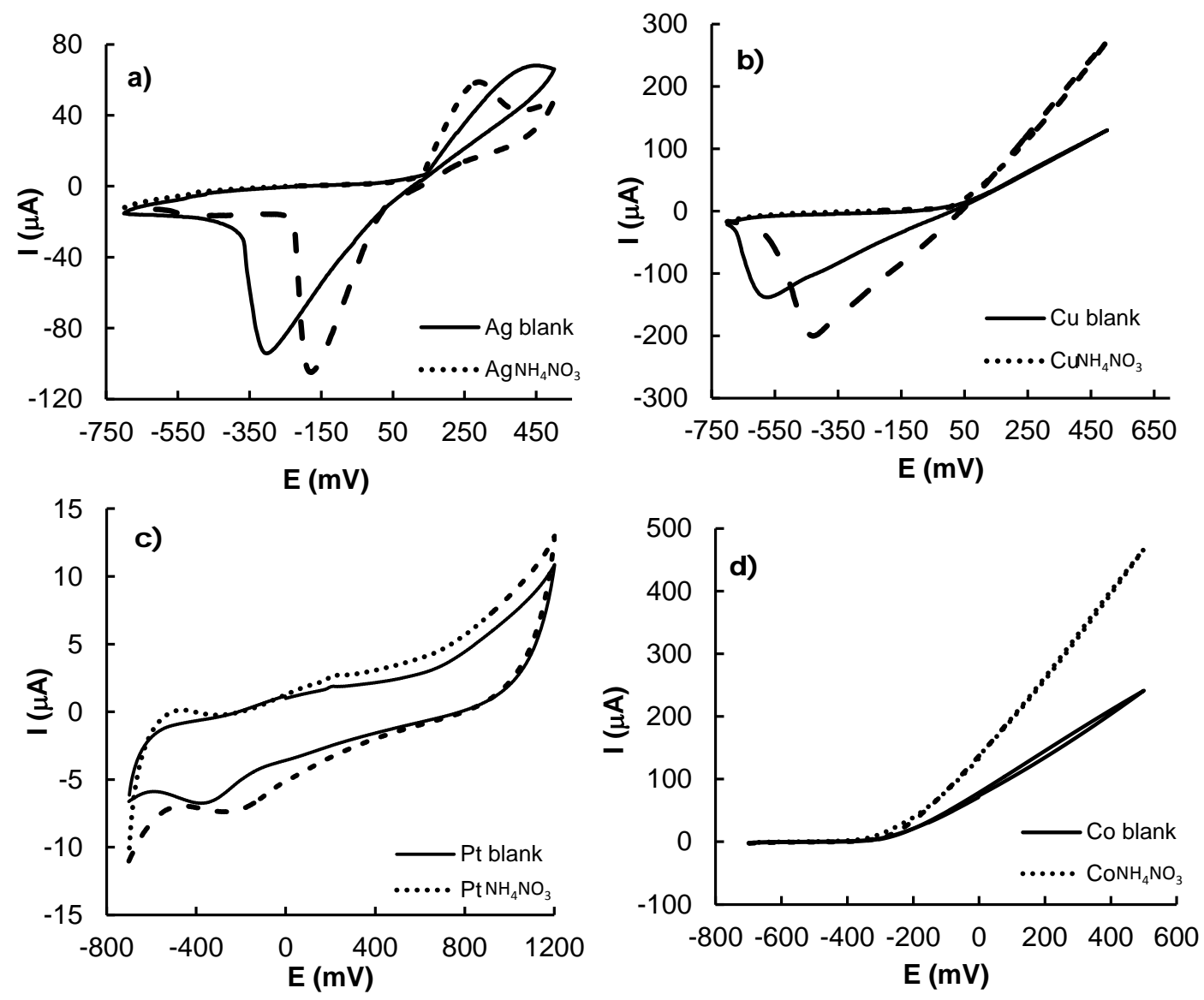
Figure 2. Cont.

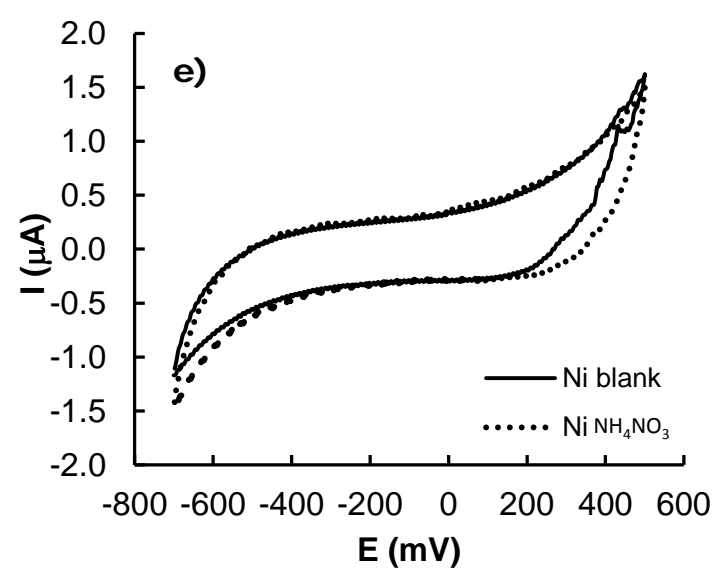

\subsection{Waveform Design}

In previous works, we have demonstrated the importance of applying a suitable set of pulses in the electronic tongue in order to be able to detect certain compound in solution [16]. With this concept in mind, the waveform used in the discrimination of $\mathrm{NH}_{4} \mathrm{NO}_{3}$ was designed using the electrochemical response found for $\mathrm{NH}_{4} \mathrm{NO}_{3}$ in the voltammetric studies described above. Figure 3a shows the sequence of pulses used in the electrochemical tongue. Pulses 2 and 3, with values of 288 and $-167 \mathrm{mV}$, respectively, were selected bearing in mind the corresponding oxidation and reduction peaks when a silver electrode was used. Pulses 5 and 6, having a potential of 300 and $-433 \mathrm{mV}$ were related with the redox processes observed for $\mathrm{NH}_{4} \mathrm{NO}_{3}$ with the copper electrode. Ammonium nitrate provided a small peak at $-250 \mathrm{mV}$ (pulse 8) when platinum electrode was used. The pulse of $-500 \mathrm{mV}$ was introduced due to the presence of a small increment in current in the presence of $\mathrm{NH}_{4} \mathrm{NO}_{3}$ observed for the Pt electrode. Finally, pulses with potential of $0 \mathrm{mV}$ were added in other to obtain information about non-faradic processes. Figure 3b shows the current intensity when the waveform is applied to a sample with concentration $1 \times 10^{-2} \mathrm{~mol} \cdot \mathrm{L}^{-1}$ using as working electrode a Ni electrode.

Figure 3. (a) The applied potentials, and (b) the current response of waveform applied to a sample that contains $\mathrm{NH}_{4} \mathrm{NO}_{3}\left(\mathrm{C}=1 \times 10^{-2} \mathrm{~mol} \cdot \mathrm{L}^{-1}\right)$ when a $\mathrm{Ni}$ electrode is used.

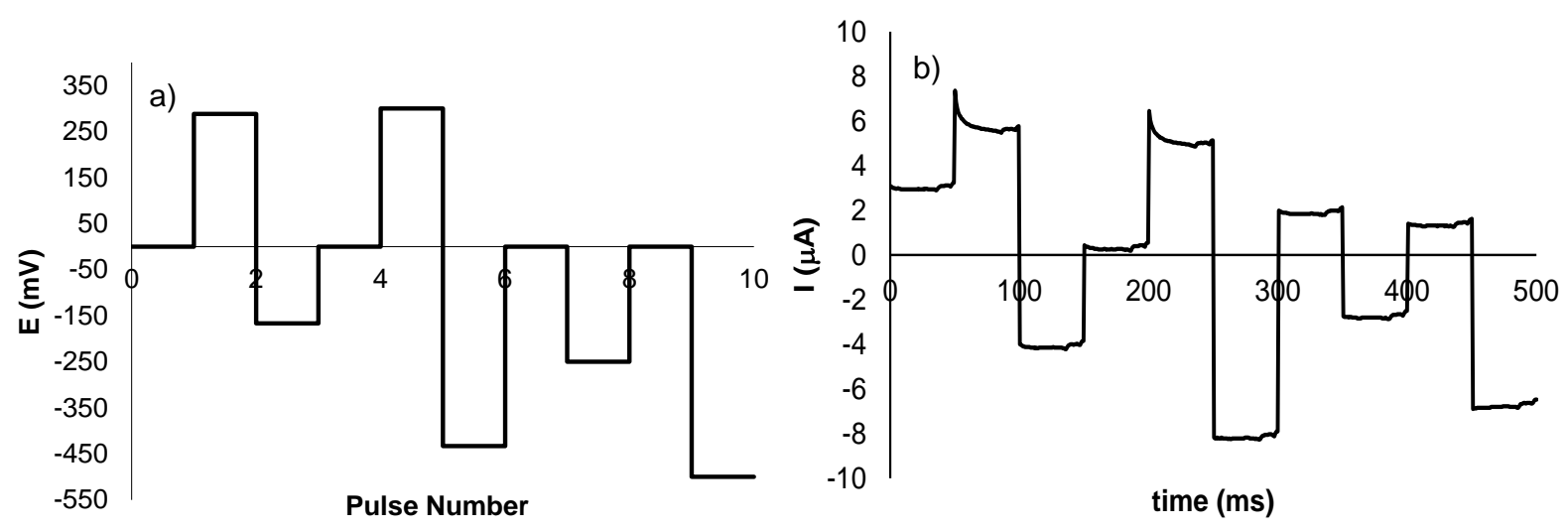




\subsection{Spontaneous Clustering with PCA}

In order to show the differential response of the tongue towards these different salts, the voltammetric electrochemical response was combined to form ensembles for pattern recognition in an attempt to find selectivity fingerprints using PCA analysis.

The PCA score plot of the results obtained from the voltammetric tongue in the presence of the selected salts (vide ante) is shown in Figure 4 for five different trials. The first principal component contained only $63.18 \%$ of the variance and the first three components represented $87.47 \%$ of total variance of the data. The three dimensions PC1, PC2 and PC3 in PCA plot were enough to differentiate the $\mathrm{NH}_{4} \mathrm{NO}_{3}$ samples. From Figure 4 it can be observed that the samples corresponding to the ammonium nitrate salt (represented by dots) appeared well separated, whereas the remaining salts (triangles) are distributed in different sites in the PCA plot. This is a promising result that suggests that the differential response in the voltammetric technique, using a set of electrodes, might be a suitable method for the detection of $\mathrm{NH}_{4} \mathrm{NO}_{3}$ in aqueous samples.

Figure 4. 3 PCA score plot of $\mathrm{NH}_{4} \mathrm{NO}_{3}$ (dots) and the remaining 14 salts (triangles) using all the electrodes.

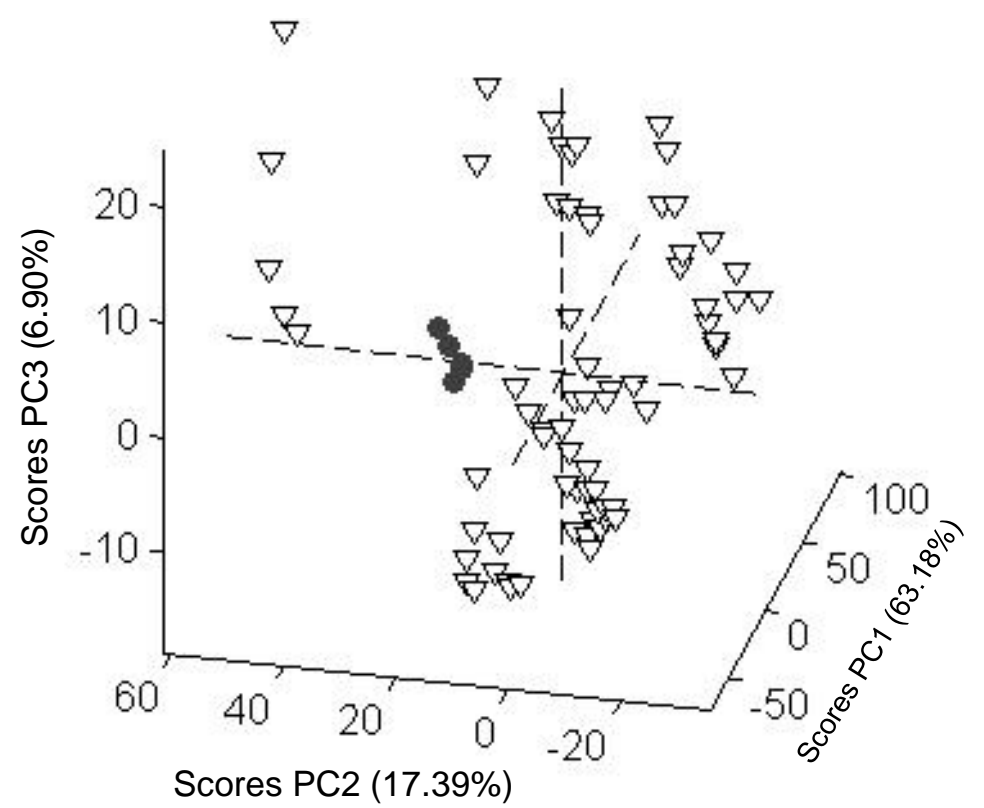

\subsection{Fuzzy Artmap Analysis}

In addition to PCA, a quantitative analysis of the electronic tongue discriminatory power was carried out by means of artificial neural networks. For this purpose a neural network was developed to analyze the data obtained from the electronic tongue to determine which type of salt corresponds of the fifteen samples of the different salts analyzed. The neuronal network type used was Fuzzy-Artmap. The network uses a training step with a set of measurements and a further step for validation. For each measurement, a vector of 4,800 data points enters the network and it tries to determine to which type of solution corresponds through 15 digital outputs. This process is repeated with the rest of the measurements, so that the activated output will have the value of "one" and the not activated outputs will have "zero" value (See Figure 5). 
Figure 5. Classification of measures by Artificial Neural Networks accord the fifteen salts.

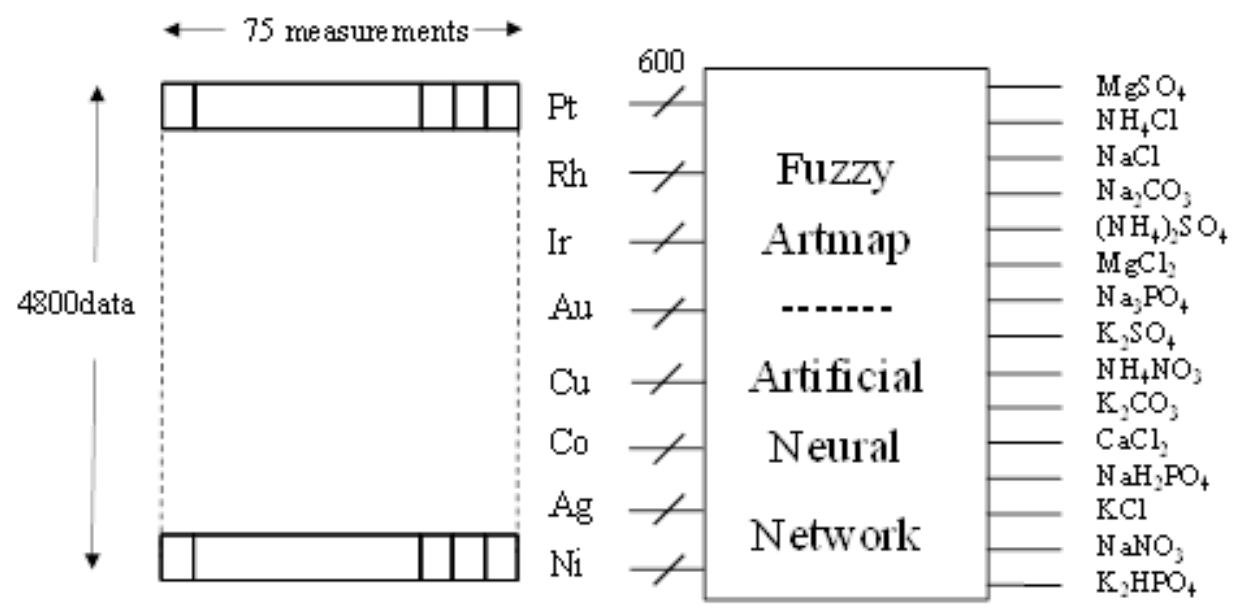

The network was implemented in-house using function macros from basic functions of Matlab [25,26]. Table 1 displays the correct classification of each analyzed salt (outputs) calculated using (i) the whole set of eight electrodes; (ii) using only the noble metals electrodes (Pt, Rh, Ir and $\mathrm{Au}$ ) and (iii) the non-noble metals electrodes $(\mathrm{Cu}, \mathrm{Co}, \mathrm{Ag}$ and $\mathrm{Ni})$. Table 1 also shows the classification obtained when a combination of 4 selected electrodes ( $\mathrm{Pt}, \mathrm{Cu}$, $\mathrm{Co}$ and $\mathrm{Ni}$ ) was used. This latter selection was carried out taking into account the relatively good classification that was observed when using this specific combination of electrodes.

Table 1 shows how the different samples (five samples) of the different salt are correctly classified using the leave-one-out cross-validation technique. In general it was observed that non-noble metals displayed a better classification than when only noble metals were used. Besides, the better classification was observed when all the electrodes or the combination of $\mathrm{Pt}, \mathrm{Cu}, \mathrm{Co}$ and $\mathrm{Ni}$ electrodes were employed. In that latter case a total of 59 samples (74.6\% success ratio bearing in mind all salts) were correctly classified. Moreover in terms of $\mathrm{NH}_{4} \mathrm{NO}_{3}$ classification the best results were found when using the signals from the $\mathrm{Pt}, \mathrm{Cu}, \mathrm{Co}$ and $\mathrm{Ni}$ metals (in this case all five samples were correctly classified) whereas the use of other combination of electrodes provided worse results. The good classification performance when using $\mathrm{Pt}, \mathrm{Cu}$, Co and Ni electrodes is most likely due to the selected potential pulses. The applied waveform was designed form the electrochemical information of cyclic voltammetry where these electrodes provide clear redox responses.

To further test the classification power of the electronic tongue, $\mathrm{NH}_{4} \mathrm{NO}_{3}$ samples (five samples) were attempted to be classified when they were compared with the five samples of a certain salt. Following this approach 14 tests were performed by comparison between $\mathrm{NH}_{4} \mathrm{NO}_{3}$ samples with the remaining 14 salts resulting in a total of 140 classifications. The analysis was performed separately using all electrodes and only the response obtained from the $\mathrm{Pt}, \mathrm{Cu}, \mathrm{Co}$ and $\mathrm{Ni}$ electrodes. The result of this analysis is shown in Table 2. When all the salts and all the electrodes were taken into account a total of 117 from 140 samples were correctly classified (83.57\%), whereas when only the set of Pt, Cu, Co and Ni metals were considered 132 from 140 samples (94.28\%) were correctly classified. These results point towards a fairly good classification of the $\mathrm{NH}_{4} \mathrm{NO}_{3}$ solutions when compared individually with solutions of other salts. 
Table 2. Number of successful in the discrimination of several salts using different combination of electrodes.

\begin{tabular}{ccccc}
\hline Sample & All Electrodes & Noble Metals & Non-Noble Metals & Pt, Cu, Co and Ni \\
\hline $\mathrm{MgSO}_{4}$ & 3 & 0 & 4 & 5 \\
$\mathrm{NH}_{4} \mathrm{Cl}$ & 5 & 3 & 4 & 5 \\
$\mathrm{NaCl}$ & 3 & 2 & 3 & 2 \\
$\mathrm{Na}_{2} \mathrm{CO}_{3}$ & 3 & 3 & 4 & 5 \\
$\left(\mathrm{NH}_{4}\right)_{2} \mathrm{SO}_{4}$ & 5 & 3 & 4 & 5 \\
$\mathrm{MgCl}_{2}$ & 5 & 5 & 4 & 5 \\
$\mathrm{Na}_{3} \mathrm{PO}_{4}$ & 5 & 5 & 5 & 5 \\
$\mathrm{~K}_{2} \mathrm{SO}_{4}$ & 2 & 0 & 3 & 0 \\
$\mathrm{NH}_{4} \mathrm{NO}_{3}$ & 4 & $\mathbf{1}$ & 4 & 5 \\
$\mathrm{~K}_{2} \mathrm{CO}_{3}$ & 5 & 3 & 3 & 4 \\
$\mathrm{CaCl}_{2}$ & 4 & 3 & 4 & 4 \\
$\mathrm{NaH}_{2} \mathrm{PO}_{4}$ & 5 & 5 & 3 & 5 \\
$\mathrm{KCl}$ & 2 & 2 & 3 & 2 \\
$\mathrm{NaNO}_{3}$ & 4 & 2 & 3 & 2 \\
$\mathrm{~K}_{2} \mathrm{HPO}_{4}$ & 4 & 3 & 3 & 5 \\
\hline $\mathrm{Total}$ & $59(78.6 \%)$ & $40(53.3 \%)$ & $54(72 \%)$ & $59(78.6 \%)$ \\
\hline
\end{tabular}

\subsection{PLS Analysis}

Encouraged by the obtained results in terms of classification of solutions containing the $\mathrm{NH}_{4} \mathrm{NO}_{3}$ explosive, we further completed our study by using partial least squares (PLS) techniques in an attempt to establish a correlation between the voltammetric measurements and the concentration of $\mathrm{NH}_{4} \mathrm{NO}_{3}$ in aqueous solution. Besides, this study was carried out using different mixtures of $\mathrm{NH}_{4} \mathrm{NO}_{3}, \mathrm{NaCl}$ and $\mathrm{NH}_{4} \mathrm{Cl}$. With this objective in mind, 20 standard solutions were prepared by addition of the three selected compounds $\left(\mathrm{NH}_{4} \mathrm{NO}_{3}, \mathrm{NaCl}\right.$ and $\left.\mathrm{NH}_{4} \mathrm{Cl}\right)$ into phosphate buffer $10^{-2} \mathrm{~mol} \cdot \mathrm{L}^{-1}$ at three different levels; i.e., blank, low $\left(1 \times 10^{-3} \mathrm{~mol} \cdot \mathrm{L}^{-1}\right)$, medium $\left(5 \times 10^{-3} \mathrm{~mol} \cdot \mathrm{L}^{-1}\right)$ and high $\left(1 \times 10^{-2} \mathrm{~mol} \cdot \mathrm{L}^{-1}\right)$. The content of each salt and its concentration was designed by using the experimental design program MODDE 8.0. PLS prediction models were created from the experimental data collected from the response in solution of the $\mathrm{Pt}, \mathrm{Cu}$, Co and $\mathrm{Ni}$ electrodes.

For a PLS calibration the information from the concentration values is introduced into the calculation via the so-called latent variables. The number of latent variables in PLS is a parameter of the procedure whose value is to be estimated from the calibration data. According to cross-validate variance studies, 7 latent variables have been used for create the models.

The Figure 6 shows the plot score of prediction model of $\mathrm{NH}_{4} \mathrm{NO}_{3}$ (predicted versus real concentration) and linear fitting in water ( $\mathrm{pH} 7$, phosphate buffer $10^{-2} \mathrm{~mol} \cdot \mathrm{L}^{-1}$ ) using the response observed from the Pt, $\mathrm{Cu}$, Co and $\mathrm{Ni}$ electrodes using a set of different mixtures containing $\mathrm{NH}_{4} \mathrm{NO}_{3}$, $\mathrm{NaCl}$ and $\mathrm{NH}_{4} \mathrm{Cl}$ salts. Besides, Table 3 shows the results of prediction for the salts $\mathrm{NH}_{4} \mathrm{NO}_{3}, \mathrm{NaCl}$ and $\mathrm{NH}_{4} \mathrm{Cl}$ in terms of linear fitting parameters. In this context, a simple way to analyze the PLS prediction is to use a linear model (i.e., $\mathrm{y}=\mathrm{p} 1 \mathrm{x}+\mathrm{p} 2$ ) in order to adjust the predicted $v$ s. the real concentration data shown in Figure 6. 
Figure 6. Plot score of prediction model of $\mathrm{NH}_{4} \mathrm{NO}_{3}$ (predicted versus real concentration) and linear fitting in water ( $\mathrm{pH} 7$, phosphate buffer $10^{-2} \mathrm{~mol} \cdot \mathrm{L}^{-1}$ ) employing the response observed from the $\mathrm{Pt}, \mathrm{Cu}, \mathrm{Co}$ and $\mathrm{Ni}$ electrodes using a set of different mixtures containing $\mathrm{NH}_{4} \mathrm{NO}_{3}, \mathrm{NaCl}$ and $\mathrm{NH}_{4} \mathrm{Cl}$ salts.

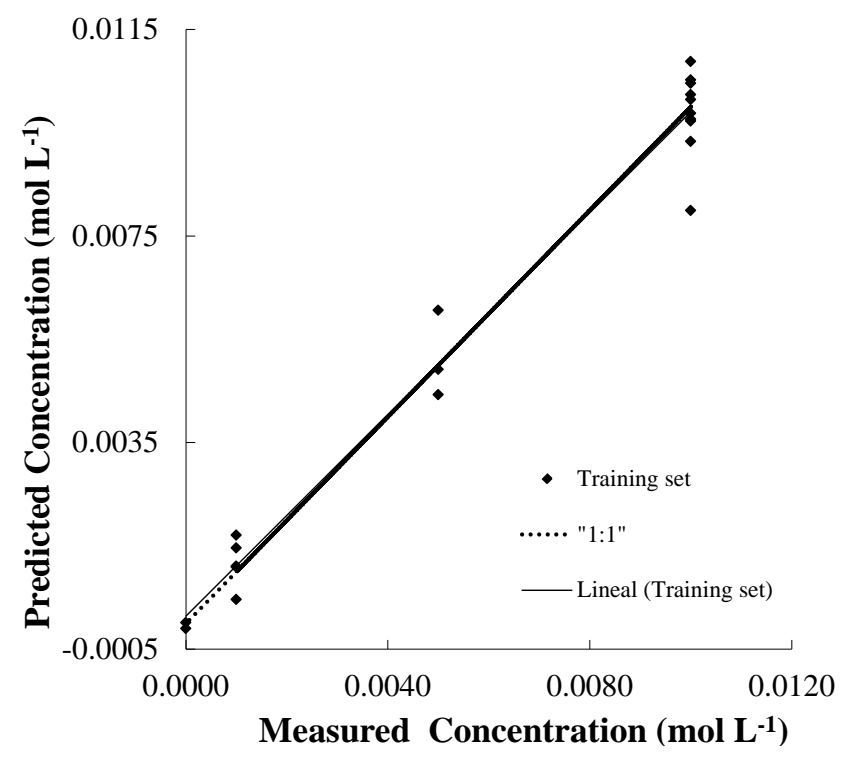

Table 3. Number of successful classification in the discrimination of $\mathrm{NH}_{4} \mathrm{NO}_{3}$ when compared with different salts.

\begin{tabular}{cc|c}
\hline Samples & All Electrodes & $\mathbf{P t ,} \mathbf{C u}, \mathbf{C o}$ and Ni Electrodes \\
\hline $\mathrm{MgSO}_{4}$ & 9 & 9 \\
$\mathrm{NH}_{4} \mathrm{Cl}$ & 7 & 9 \\
$\mathrm{NaCl}$ & 9 & 9 \\
$\mathrm{Na}_{2} \mathrm{CO}_{3}$ & 10 & 10 \\
$\left(\mathrm{NH}_{4}\right)_{2} \mathrm{SO}_{4}$ & 7 & 9 \\
$\mathrm{MgCl}_{2}$ & 7 & 10 \\
$\mathrm{Na}_{3} \mathrm{PO}_{4}$ & 10 & 10 \\
$\mathrm{~K}_{2} \mathrm{SO}_{4}$ & 9 & 9 \\
$\mathrm{~K}_{2} \mathrm{CO}_{3}$ & 9 & 10 \\
$\mathrm{CaCl}_{2}$ & 9 & 10 \\
$\mathrm{NaH}_{2} \mathrm{PO}_{4}$ & 9 & 10 \\
$\mathrm{KCl}_{2}$ & 8 & 8 \\
$\mathrm{NaNO}_{3}$ & 8 & 9 \\
$\mathrm{~K}_{2} \mathrm{HPO}_{4}$ & 9 & 10 \\
\hline $\mathrm{Total}^{2}$ & $117 / 140(83.57 \%)$ & $132 / 140(94.28 \%)$ \\
\hline
\end{tabular}

Table 4. Parameters from the linear fitting of prediction data from the PLS analysis using $\mathrm{Pt}, \mathrm{Co}, \mathrm{Cu}$ and Ni electrodes.

\begin{tabular}{ccccc}
\hline & $\mathbf{r}^{2}$ & Slope (p1) & Intercept (p2) $\times \mathbf{1 0}^{-4} \mathbf{( M )}$ & RMSECV $\times \mathbf{1 0}^{-\mathbf{3}} \mathbf{( M )}$ \\
\hline $\mathrm{NH}_{4} \mathrm{NO}_{3}$ & 0.977 & 0.9768 & 1.3 & 6.45 \\
$\mathrm{NaCl}$ & 0.987 & 0.9873 & 1.9 & 4.8 \\
$\mathrm{NH}_{4} \mathrm{Cl}$ & 0.984 & 0.9842 & 0.9 & 5.4 \\
\hline
\end{tabular}


In this model p1 is the slope of the curve fitting and p2 the intercept. In PLS analysis, when closer to 1 are the slopes and closer to 0 are the intercept, more accurate is the calibration model. Additionally the following figures also show the correlation coefficient $\left(\mathrm{r}^{2}\right)$ and the root mean square error of cross-validation (RMESCV), which represents the goodness of the fit. These last parameters are a useful tool for evaluating the precision of predictions since it represents the error in the confidentiality of the model. A simple visual inspection of the spread of the experimental points along the straight line (reference line) in Figure 6 shows an accurate prediction in the concentration of $\mathrm{NH}_{4} \mathrm{NO}_{3}$. As shown Table 4, this precise prediction can be confirmed by the relatively low values of the RMSECV and the p1, slope of the curve, coefficients that are close to 1 . Table 3 also shows good fitting parameters from the PLS analysis using $\mathrm{Pt}, \mathrm{Co}, \mathrm{Cu}$ and $\mathrm{Ni}$ electrodes for the prediction of concentrations of $\mathrm{NaCl}$ and $\mathrm{NH}_{4} \mathrm{Cl}$ salts.

\section{Conclusions}

A protocol to detect and quantify of $\mathrm{NH}_{4} \mathrm{NO}_{3}$ in aqueous samples is proposed here. The method consists of the use of a voltammetric electronic tongue based in a set of simple metallic electrodes. PCA analysis showed the capability of the electronic tongue to detect the presence of $\mathrm{NH}_{4} \mathrm{NO}_{3}$ in water and discriminate this compound from other common inorganic salts, i.e., $\mathrm{MgSO}_{4}, \mathrm{NH}_{4} \mathrm{Cl}, \mathrm{NaCl}$, $\mathrm{Na}_{2} \mathrm{CO}_{3},\left(\mathrm{NH}_{4}\right)_{2} \mathrm{SO}_{4}, \mathrm{MgCl}_{2}, \mathrm{Na}_{3} \mathrm{PO}_{4}, \mathrm{KSO}_{4}, \mathrm{NH}_{4} \mathrm{NO}_{3}, \mathrm{~K}_{2} \mathrm{CO}_{3}, \mathrm{CaCl}_{2}, \mathrm{NaH}_{2} \mathrm{PO}_{4}, \mathrm{KCl}, \mathrm{NaNO}_{3}$, $\mathrm{K}_{2} \mathrm{HPO}_{4}$. In addition to PCA studies, a quantitative analysis of the electronic tongue discrimination ability was carried out by means of artificial neural networks using the leave-one-out cross-validation technique. A good discrimination of $\mathrm{NH}_{4} \mathrm{NO}_{3}$ against other salts when using the electrochemical response of a combination of four selected electrodes (Pt, $\mathrm{Cu}, \mathrm{Co}$ and $\mathrm{Ni}$ ) was found. Finally PLS data analysis using three compounds $\left(\mathrm{NH}_{4} \mathrm{NO}_{3}, \mathrm{NH}_{4} \mathrm{Cl}\right.$ and $\left.\mathrm{NaCl}\right)$ at three concentration levels showed a fairly good accurate concentration prediction for $\mathrm{NH}_{4} \mathrm{NO}_{3}$ in water samples. These results suggested that voltammetric electronic tongues could be useful for the detection of $\mathrm{NH}_{4} \mathrm{NO}_{3}$ in aqueous environments and pointed towards the possibility that this, or similar tongue-based systems, could be of application for the detection of $\mathrm{NH}_{4} \mathrm{NO}_{3}$ in real explosive formulation samples.

\section{Conflict of Interest}

The authors declare no conflict of interest.

\section{References}

1. Fedroff, B.T. Encyclopedia of Explosives and Related Items; Picatinny Arsenal: Dove, NJ, USA, 1960; Volume 1, pp. A311-A379.

2. Akhavan, J. The Chemistry of Explosives, 2nd ed.; Royal Society of Chemistry: Cambridge, UK, 2004.

3. Fordham, S. High Explosives and Propellants; Pergamon: London, UK, 1996.

4. Ullmann's Encyclopedia of Industrial Chemistry, 5th ed.; Wiley VCH: Weinheim, Germany, 1988; Volume A10, p. 165. 
5. Kirk-Othmer Encyclopedia of Chemical Technology, 4th ed.; Wiley: New York, NY, USA, 1992; Volume 10, p. 49.

6. Rocha, F.R.P.; Reis, B.F. A flow system exploiting multicommutation for speciation of inorganic nitrogen in waters. Anal. Chim. Acta 2000, 409, 227-235.

7. Michalski, R.; Kurzyca, I. Determination of nitrogen species (nitrate, nitrite and ammonia ions) in environmental samples by ion chromatography. Pol. J. Environ. Stud. 2006, 15, 5-18.

8. Fritz, J.S.; Gjerde, D.T. Ion Chromatography; Wiley-VCH: Weinheim, Germany, 2000.

9. $\mathrm{Xu}, \mathrm{Q}$.; Zhang, W.; Xu, C.; Jin, L. Continuous and simultaneous determination of anions and cations in rainwater by ion chromatography. Analyst 2000, 125, 1065-1069.

10. Mou, S.; Wang, H.; Sun, Q. Simultaneous determination of the three main inorganic forms of nitrogen by ion chromatography. J. Chromatogr. 1993, 640, 161-166.

11. Isildak, I.; Asan, A. Simultaneous detection of monovalent anions and cations using all solid-state contact PVC membrane anion and cation-selective electrodes as detectors in single column ion chromatography. Talanta 1999, 48, 967-978.

12. Winquist, F.; Wide, P; Lundström, I. An electronic tongue based on voltammetry. Anal. Chim. Acta 1997, 357, 21-31.

13. Salinas, Y; Climent, E.; Martínez-Máñez, R.; Sancenón, F.; Marcos, M.D.; Soto, J.; Costero, A.M.; Gil, S.; Parra, M.; Pérez de Diego, A. Highly selective and sensitive chromo-fluorogenic detection of the tetryl explosive using functional silica nanoparticles. Chem. Commun. 2011, 47, 11885-11887.

14. Salinas, Y; Martínez-Máñez, R.; Marcos, M.D.; Sancenón, F.; Costero, A.M.; Parra, M.; Gil, S. Optical chemosensors and reagents to detect explosives. Chem. Soc. Rev. 2012, 41, 1261-1296.

15. Climent, E.; Martí, A.; Royo, S.; Martínez-Máñez, R.; Marcos, M.D.; Sancenón, F.; Soto, J.; Costero, A.M.; Gil, S.; Parra, M. Chromogenic detection of nerve agent mimics by mass transport control at the surface of bifunctionalized silica nanoparticles. Angew. Chem. Int. Ed. 2010, 49, 5945-5948.

16. Campos, I.; Masot, R.; Alcañiz, M.; Gil, L.; Soto, J.; Vivancos, J.L.; García-Breijo, E.; Labrador, R.H.; Barat, J.M.; Martínez-Máñez, R. Accurate concentration determination of anions nitrate, nitrite and chloride in minced meat using a voltammetric electronic tongue. Sens. Actuators B: Chem. 2010, 149, 71-78.

17. Campos, I.; Alcañiz, M.; Aguado, D.; Barat, R.; Ferrer, J.; Gil, L.; Marrakchi, M.; Martínez-Mañez, R.; Soto, J.; Vivancos, J.L. A voltammetric electronic tongue as tool for water quality monitoring in wastewater treatment plants. Water Res. 2012, 46, 2605-2614.

18. Martínez-Máñez, R.; Soto, J.; Garcia-Breijo, E.; Gi, L.L.; Ibáñez, J.; Llobet, E. An "electronic tongue” design for the qualitative analysis of natural waters. Sens. Actuators B: Chem. 2005, 104, 302-307.

19. Toko, K. Taste sensor. Sens. Actuators B: Chem. 2000, 64, 205-215.

20. Scampicchio, M.; Benedetti, S.; Brunetti, B.; Mannino, S. Amperometric electronictongue for the evaluation of the tea astringency. Electroanalysis 2006, 18, 1643-1648.

21. Ivarsson, P.; Holmin, S.; Hojer, N.E.; Krantz-Rulcker, C.; Winquist, F. Discrimination of tea by means of a voltammetric electronic tongue and different applied waveforms. Sens Actuators B: Chem. 2000, 76, 449-454. 
22. Carpenter, G.; Grossberg, S.; Markuzon, N.; Reynolds, J.; Rosen, D. Fuzzy ARTMAP: A neural network architecture for incremental supervised learning of multidimensional maps. IEEE Trans. Neural Netw. 1992, 3, 698-713.

23. Carpenter, G.A.; Grossberg, S. Fuzzy ARTMAP: A Synthesis of Neural Networks and Fuzzy Logic for Supervised Categorization and Nonstationary Prediction. In Fuzzy Sets, Neural Networks, and Soft Computing; Yager, R.R., Zadeh, L.A., Eds.; Van Nostrand-Reinhold: New York, NY, USA, 1994; pp. 126-165.

24. Llobet, E.; Hines, E.L.; Gardner, J.W.; Bartlett, P.N.; Mottram, T.T. Fuzzy ARTMAP based electronic nose data analysis. Sens. Actuators B: Chem. 1999, 61, 183-190.

25. Geladi, P.; Kowalski, B.R. Partial least-squares regression: A tutorial. Anal. Chim. Acta 1986, 185, 1-17.

26. Vinaixa, M.; Llobet, E.; Brezmes, J.; Vilanova, X.; Correig, X. A fuzzy ARTMAP- and PLS-based MS e-nose for the qualitative and quantitative assessment of rancidity in crisps. Sens. Actuators B: Chem. 2005, 106, 677-686.

(C) 2013 by the authors; licensee MDPI, Basel, Switzerland. This article is an open access article distributed under the terms and conditions of the Creative Commons Attribution license (http://creativecommons.org/licenses/by/3.0/). 